\title{
Wavelength-specific behaviour in Lepeophtheirus salmonis and Calanus finmarchicus to ultraviolet and visible light in laboratory experiments (Crustacea: Copepoda)
}

\author{
Knut A. Aarseth ${ }^{1, *}$, Thomas A. Schram ${ }^{2}$ \\ ${ }^{1}$ Agricultural University of Norway, PO Box 5065, 1432 Aas, Norway \\ ${ }^{2}$ Department of Biology, Section of Marine Zoology and Marine Chemistry, University of Oslo, \\ PO Box 1064 Blindern, 0316 Oslo, Norway
}

\begin{abstract}
The significance of ultraviolet light as a cue in diel vertical migration of free-swimming copepodids of the ectoparasite salmon louse Lepeophtheirus salmonis (Kroyer) and adults of the holopelagic Calanus finmarchicus (Gunnerus) were examined in the laboratory. Copepodids of salmon lice were photopositive in $1 \mathrm{~m}$ deep water columns when illuminated with visible light (VIS) only, but when VIS was combined with ultraviolet light, with a spectral irradiance maximum at $313 \mathrm{~nm}$, the copepodids gathered significantly deeper in the water column. In similar experiments $C$. finmarchicus did not show upward migration as a response to VIS, and a combination with ultraviolet light did not alter their normal behaviour. In $250 \mathrm{ml}$ beakers, however, C. finmarchicus showed avoidance behaviour upon being exposed to UV-light; the copepods swam vigorously with prosome pointing downwards as if they were trying to escape from the irradiation. We conclude that these copepods must have sensory structures not yet described which can detect UV-radiation. Possible implications of these findings are discussed in relation to vertical migration and to host-finding in the salmon louse.
\end{abstract}

KEY WORDS: Copepods - Calanus finmarchicus - Lepeophtheirus salmonis - Diel vertical migration UVR

\section{INTRODUCTION}

Diel vertical migration in copepods is a well-known phenomenon (Cushing 1951); the normal pattern is a deeper daytime depth than during the dark hours, with a descent around sunrise and an ascent near sunset. Ringelberg (1995) outlined the necessity of considering different causal factors when approaching the subject of diel vertical migration (DVM). As the primary causal factor triggering off DVM, Ringelberg (1995) suggested the maximum relative change in light intensity at dawn and dusk. Forward (1988) has also reviewed how light could influence DVM. Ringelberg (1995) considered the significance of the presence of preda-

•E-mail: knut.aarseth@itf.nlh.no tors and of food concentration as secondary causal factors. The adaptive value of DVM, toward avoiding predators and optimising metabolism, has been discussed extensively and reviewed by Lampert (1989).

The migration pattern in pelagic crustaceans is diverse, comprising the nocturnal DVM and a dawn rise prior to the descent, as is known for Calanus finmarchicus (Cushing 1951). But the reverse pattern has been reported for Pseudocalanus sp. (Ohman et al. 1983). In addition to sunlight, migration in copepods can be triggered by moonlight (Jerling \& Wooldridge 1992), but negative evidence of a lunar effect has also been reported (Zaret \& Suffern 1976). DVM can be induced by the presence of planktivore fish, both as a phenotypic response (Bollens et al. 1992) and as a genotypic response (Stich \& Lampert 1981). Thus the identification of a primary causal factor explaining the 
vertical migration mechanism in crustaceans should reflect the diversity and plasticity in their phototactic behaviours.

Jerlov (1950) points out the potential hazard of ultraviolet radiation to marine organisms after measuring UV-B irradiation down to $20 \mathrm{~m}$ depth in the eastern Mediterranean, and early work with copepods has given positive evidence of the lethal effect of ambient ultraviolet light (Brooker Klugh 1929). These findings have been confirmed in the laboratory (Dey et al. 1988) and in situ for a freshwater copepod (Williamson et al. 1994). It has, however, been reported that copepods are not capable of avoiding the damaging UV-B irradiation by downward migration. Damkaer \& Dey (1982) found the copepod Epilabidocera longipedata to be photopositive when exposed to a combination of visible light and UV-B in the laboratory, but different patterns have been reported for other taxa. The echinoid larvae of the sand dollar Dendraster excentricus reacted to UV-B by downward migration (Pennington. \& Emlet 1986). Similar findings have been published for 3 different clones of the freshwater cladoceran Daphnia pulex (Hessen 1994).

Echinoids have receptors that are directly photosensitive to UV-B (Yoshida \& Millot 1959, in Pennington \& Emlet 1986), and UV-receptors have been found among crustaceans with compound eyes. Cromin et al. (1994) found that mantis shrimp (Stomatopoda) have UV-receptors with a sensitivity maximum at $345 \mathrm{~nm}$ (UV-A). Furthermore, the freshwater cladoceran Daphnia magna has 4 spectral sensitivity maxima: 1 is sensitive to UV-A $(348 \mathrm{~nm})$ and the remainder are sensitive to visible light $\{434,525$ and $608 \mathrm{~nm}$, Smith \& Macagno 1990). Such eyes are subject to natural selection, which could result in diverse phototactic behaviours.

Copepods have nauplius eyes (cup eyes), concave structures containing pigments and photoreceptors, and some species may have lenses (Elofsson 1966). As far as we know, the distinct photoreceptors of the nauplius eye have not yet been tested for sensitivity to different wavelengths. However, different copepods are photopositive when illuminated with visible light in the laboratory. Bron et al. (1993) have described positive phototaxis among the infective stage, i.e. the copepodids, of the salmon louse Lepeophtheirus salmonis, by examining their response to wavelengths between 400 and $700 \mathrm{~nm}$. The authors also revealed increased photopositive response with increased light intensity. Moreover, Stearns \& Forward (1984) found that the pelagic copepod Acartia tonsa was photopositive when illuminated with different wavelengths of visible light in the laboratory. A. tonsa is known to undertake DVM in nature, and the photopositive response has been suggested to be a laboratory artefact (Forward 1988).
Lepeophtheirus salmonis is an obligate ectoparasitic copepod on salmonids in the Northern Hemisphere (Kabata 1979). It is thus found on Atlantic salmon Salmo salar (Schram 1993a) as well as on species of Pacific salmon (Nagasawa et al. 1993). The salmon louse belongs to the order Siphonostomatoida and the family Caligidae, and their life cycle comprises 10 stages from hatching. Three stages are pelagic ( 2 nauplius, and the infesting copepodid), 4 chalimus stages fixed to the host and finally 3 stages are mobile on the host ( 2 preadult and the adult) (Schram 1993b). It is assumed that the copepodids are found in surface waters in nature (Heuch et al. 1995).

The holopelagic Calanus finmarchicus is known to undergo ontogenetic vertical migration, and it has 6 nauplius stages in surface waters, followed by 5 copepodid stages and the adult, where the Copepodid $\mathrm{V}(\mathrm{CV})$ is the overwintering stage inhabiting deep water. Both salmon lice and $C$. finmarchicus are of commercial importance: $C$. finmarchicus nauplii are used to feed larval stages of economically valuable fish species like cod Gadus morhua, while salmon lice induce considerable costs to the salmon farming industry annually. Both species are exposed to UV-irradiation during their lifetime.

Here we present experimental evidence of wavelength-specific behaviour in Calanus finmarchicus and in salmon louse copepodids. We discuss the significance of these findings, with emphasis on the copepodid light-sensitive organ (nauplius eye), in relation to DVM in C. finmarchicus and host-finding in the salmon louse.

\section{MATERIALS AND METHODS}

Calanus finmarchicus (Stage CV) were caught with a WP-2 net $(200 \mu \mathrm{m})$ (Fraser 1968) in vertical hauls from $80 \mathrm{~m}$ depth in the inner Oslofjord $\left(59^{\circ} 49^{\prime} \mathrm{N}, 10^{\circ} 35^{\prime} \mathrm{E}\right)$, from RV 'Trygve Braarud' (University of Oslo), on 27 March 1995 at noon. The net was closed below the pycnocline to avoid contamination of samples with phytoplankton. Lepeophtheirus salmonis eggs were hatched in the laboratory at the Department of Biology, in a maturation and hatching system described by Heuch et al. (1995).

Perception of ultraviolet light and vertical migration were studied in $1 \mathrm{~m}$ high experimental chambers as described by Heuch (1995). The columns were fitted with 3 valves each. When closed, they divided the column vertically in four $25 \mathrm{~cm}$ sections. An UV fluorescent tube with spectral irradiance maximum at $313 \mathrm{~nm}$, manufactured by Q-Panel Co., USA, and a cool white light tube $(30 \mathrm{~W})$ were mounted side by side in a lamp house with reflector, and suspended $0.5 \mathrm{~m}$ above the water 
columns. The UV-B intensity was measured with a Vilber-Lourmat VLX-3 radiometer with peak sensitivity at $312 \mathrm{~nm}$. The same instrument was used to determine the outdoor irradiance to assess realistic UV-doses. Visible light was measured with a Licor instrument, Model $185 \mathrm{~B}$. The experiments where conducted in cold-storage chambers.

In each experiment 4 replicate columns were used simultaneously. The salinity was 30.4 and the temperature $11^{\circ} \mathrm{C}$. The copepods were applied at the surface and left to acclimate for $6 \mathrm{~h}$ in dark prior to exposure for $1 \mathrm{~h}$. Two experiments were conducted for each species (salmon lice $\sim 100$ and Calanus finmarchicus $\sim 50$ individuals in each replicate): (1) illumination with visible light (VIS) (75 and $14 \mu \mathrm{mol} \mathrm{m} \mathrm{m}^{-2} \mathrm{~s}^{-1}$ measured in air at the top and at the base of the chambers respectively) and (2) exposure to the combination of VIS and UV-light (VIS: as above, and UV: $0.27 \mathrm{~kJ} \mathrm{~m}^{-2} \mathrm{~min}^{-1}$ at the top and $0.04 \mathrm{~kJ} \mathrm{~m}^{-2}$ $\min ^{-1}$ at the base of the chamber). To prevent the salmon louse copepodids from creeping out of the water, a $0.5 \mathrm{~cm}$ layer of fresh water was established on the top. Weighted mean depth (WMD $=\Sigma n_{i} d_{1} / n_{i}$, where $n_{\mathrm{i}}=$ number of individuals and $d_{1}=$ water depth) was calculated for each experiment.

Calanus finmarchicus was studied in additional experiments performed in $250 \mathrm{ml}$ flat beakers, under 3 different conditions: (1) UV-B $\left(0.2 \mathrm{~kJ} \mathrm{~m} \mathrm{~m}^{-2} \mathrm{~min}^{-1}\right)$, (2) UV-B + VIS $\left(0.2 \mathrm{~kJ} \mathrm{~m}^{-2} \mathrm{~min}^{-1}, 49 \mu \mathrm{mol} \mathrm{m} \mathrm{m}^{-2} \mathrm{~s}^{-1}\right)$ and (3) VIS (49 $\left.\mu \mathrm{mol} \mathrm{m} \mathrm{m}^{-2} \mathrm{~s}^{-1}\right)$. The water depth was $6 \mathrm{~cm}$, with a salinity of 30.4 and water temperature of $8^{\circ} \mathrm{C}$. The same lamps as in the previously described experiments (for $1 \mathrm{~m}$ high water columns) were employed. WMD was calculated for each experiment.

\section{RESULTS}

Experiments in the $1 \mathrm{~m}$ water columns showed contradictory patterns for the 2 species. Calanus finmarchicus did not alter its phototactic behaviour in the 2 light treatments (VIS and UV + VIS), whereas copepodids of salmon lice gathered significantly deeper in the water column when exposed to UV and VIS compared to those illuminated with VIS only. WMD was calculated for the respective experiments and compared in a $t$-test, where we hypothesised no difference between experiments with or without ultraviolet irradiation. The hypothesis was tested against the alternative that the copepods exposed to UV would aggregate deeper in the water column (Table 1).

As seen in Table 1, Calanus finmarchicus settled in the lower quadrant irrespective of illumination, whereas the salmon louse copepodids were located close to the surface when illuminated with visible light only (Fig. 1A). After $1 \mathrm{~h}$ illumination, about $91 \%$ of the copepodids were in the upper quadrant; in fact they gathered just below the freshwater layer (at $\sim 2 \mathrm{~cm}$ depth). Their normal behaviour was altered when copepodids were exposed to additional ultraviolet light (Fig. 1B), and only 58\% were in the upper quadrant after $1 \mathrm{~h}$. Although there were copepodids in all quadrants, the highest aggregation was observed around

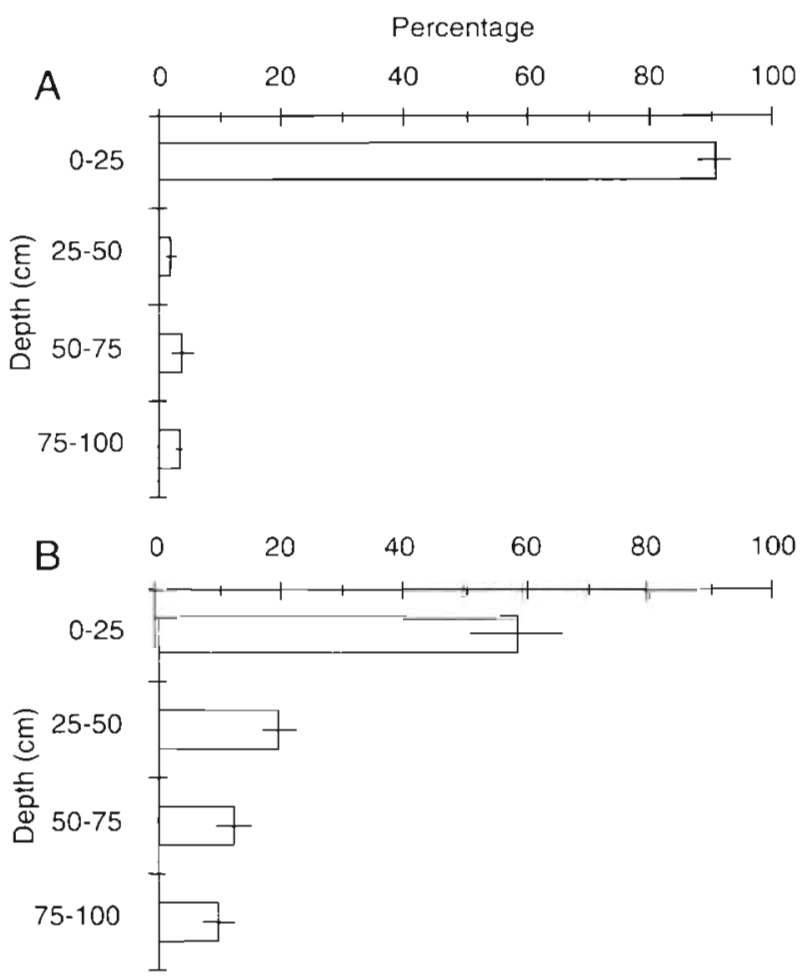

Fig. 1 Relative depth distribution $\pm \mathrm{SE}(\mathrm{n}=4)$ of Lepeophtheirus salmonis copepodids in 4 quadrants in $1 \mathrm{~m}$ high water columns after $1 \mathrm{~h}$ illumination. (A) Visible light (75 $\mu \mathrm{mol} \mathrm{s} \mathrm{s}^{-1} \mathrm{~m}^{-2}$, at the top of the chamber), (B) visible light and $\mathrm{UV}_{313 \mathrm{~nm}}\left(75 \mu \mathrm{mol} \mathrm{s}^{-1} \mathrm{~m}^{-2}, 0.27 \mathrm{~kJ} \mathrm{~m}^{-2} \mathrm{~min}^{-1}\right)$ 
$20 \mathrm{~cm}$ depth, but this result is not reflected in the calculated WMD (Table 1). The large variability in WMD between Cases 1 and 2 (40.1 and $22.3 \mathrm{~cm}$ ) can partly be explained by the location of the valves in the experimental chambers, where the upper valve is mounted at $25 \mathrm{~cm}$ depth; thus, in the region with the highest aggregation of copepodids. This means that a few centimetres difference at the depth of maximum aggregation in the respective columns influences the quadrant to which the animals are assigned. Secondly, $16 \%$ of the copepods in Case 1 where located in the lower quadrant in comparison to only $4 \%$ in Case 2 ; this also has an impact on the calculated WMD. We regard the aggregation of animals at $-20 \mathrm{~cm}$ water depth as a 'biological measure' of the attenuation of UV-light in the water column, and as the depth where the irradiation was insufficient to initiate further downward migration.

It seems quite clear that the $1 \mathrm{~m}$ columns were inadequate to examine the phototactic behaviour of Calanus finmarchicus, due to attenuation of the UV-light and insignificant irradiation at the bottom, where individuals were located. In shorter, $6 \mathrm{~cm}$ water columns, however, the copepods will inevitably be exposed to UV-light (Fig. 2). Such light seemed to trigger a stimulus for increased swimming activity away from the source compared to their normal relaxed behaviour where they were 'hanging' on their antennules. When exposed to UV-light only or in combination with VIS, the copepods reacted immediately by swimming downward as if they where trying to escape from the irradiation. Furthermore UV-irradiated copepods had their prosome pointing downwards and swam vigorously toward the bottom. After $4 \mathrm{~min}, 65$ and $70 \%$ of individuals exposed to only UV-light and UV + visible light respectively were swimming toward the bottorn of the beakers, a behaviour which was not observed among animals illuminated with visible light only. Differences
Table 2. Mean depth of Calanus finmarchicus in $6 \mathrm{~cm}$ high water columns after 4 min illumination time. Mean depth (MD) of 5 experiments was compared in a 1 -tailed $t$-test $(\mathrm{df}=8)$ [VIS:VIS + UV] and [VIS:UV]

\begin{tabular}{|lllllllll|}
\hline \multicolumn{1}{l}{ Treatment } & \multicolumn{3}{c}{ WMD } & & MD & t-test \\
\hline VIS & 32.9 & 36.5 & 42.5 & 40.5 & 43.6 & 39.2 & \\
VIS + UV & 44.5 & 52.5 & 45.5 & 52.5 & 52.5 & & 49.5 & $\mathrm{p}<0.01$ \\
UV & 52.5 & 48.8 & 44 & 52.5 & 51.5 & & 49.8 & $\mathrm{p}<0.01$ \\
\hline
\end{tabular}

in mean depth distribution between copepods illuminated with: (1) VIS versus VIS + UV and (2) VIS versus UV were both significant $(p<0.01$, Table 2$)$.

\section{DISCUSSION}

Our results indicate that copepods possess a sensory apparatus sensitive to ultraviolet light and that they were able to discriminate between the wavelengths of UV-light and visible light. Although we have not described the actual photoreceptors in the nauplius eye of Calanus finmarchicus or in the Lepeophtheirus salmonis copepodid, we regard our findings as relevant to different aspects of the ecology and physiology of zooplankton in aqueous surroundings. The aquatic environment is considered relatively homogenous and unstructured (Hutchinson 1961); however, these copepods have, in their behaviour, shown that they have the potential to exploit distinct wavelengths of light. Even though the attenuation of light in water is wavelength dependent, the accessibility of distinct wavelengths of light may rather be a function of photoreceptor sensitivity. This is a tenable theory supported by the findings of Frank \& Widder (1996), who estimated that some crustaceans could detect UV-A at $600 \mathrm{~m}$ depth. Moreover, it has been shown that the spectral

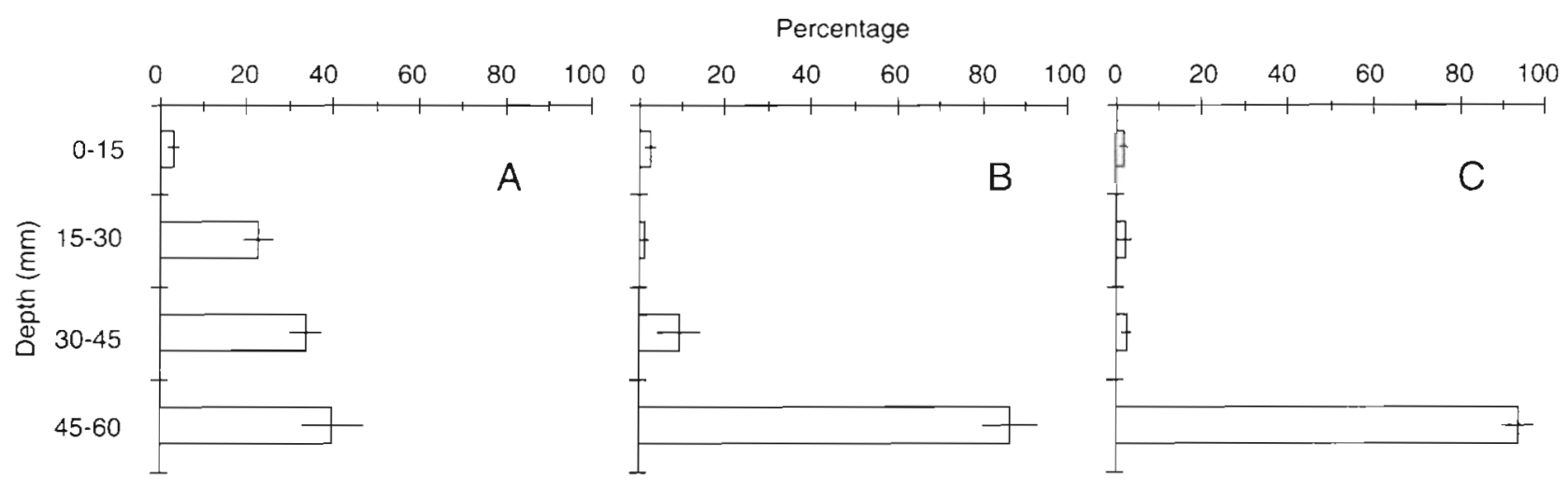

Fig. 2. Relative depth distribution $\pm \mathrm{SE}(\mathrm{n}=5)$ of Calanus finmarchicus in 4 quadrants in $6 \mathrm{~cm}$ water columns after 4 min illumination. (A) Visible light $\left(49 \mu \mathrm{mol} \mathrm{s}^{-1} \mathrm{~m}^{-2}\right\}_{1}(B)$ visible light and $U_{313 \mathrm{~mm}}\left(49 \mu \mathrm{mol} \mathrm{s}^{-1} \mathrm{~m}^{-2}, 0.2 \mathrm{~kJ} \mathrm{~m}^{-2} \mathrm{~min}^{-1}\right)$ and $(\mathrm{C}) \mathrm{UV}_{313 \mathrm{~nm}}\left(0.2 \mathrm{~kJ} \mathrm{~m} \mathrm{~min}^{-1}\right)$ 
sensitivity of photoreceptors of the freshwater cladoceran Daphnia magna varied by adaptation to distinct wavelengths of light, a species that is known to possess 4 different sensitivity maxima (Smith \& Macagno 1990). It might also be correct to assume that there must be a lower threshold intensity of distinct wavelengths to trigger off a response. Such a mechanism would be in accordance with the explanation we gave for the observed aggregation of salmon louse copepodids at $20 \mathrm{~cm}$ depth, which we interpreted as a 'biological measure' of the depth at which the UV-light intensity was insufficient to trigger further downward migration.

Structures adapted to capture photons of distinct wavelengths are located in retinular cells. Such cells and pigment cells are always present in crustacean nauplius eyes (cup eyes), and additional lenses are present in ostracods and in a few copepod species, e.g. Calanus finmarchicus (Elofsson 1966). In addition, the ostracod nauplius eye is described as having tapetal cells (mirror); these tapetal cells have been regarded as diagnostic for the maxillopod-ostracod group and suggest that the animals are capable of image formation (Anderson \& Nilsson 1981). The salmon louse Lepeophtheirus salmonis possesses both tapetal cells and lenses (Bron et al. 1993). The nauplius eye of the salmon louse has 2 eye cups, with large lenses dorsally and a single ventral cup without lens, suggesting the possibility of image formation dorsally. The significance of possessing both tapetal cells and lenses for image formation has recently been discussed by Dawkins (1996).

Cronin et al. (1994) suggested that UV contrast vision might be useful for enhancing the visual contrast of midwater predators or prey. This view might also be extended to include host-finding in parasitic species that are sensitive to ultraviolet light and possess eye structures necessary to form images. It is known that salmon louse copepodids are located in the depth range where UV vision is possible in coastal waters (Heuch et al. 1995). The results of our experiments with salmon lice could indicate that the adaptive value of their behaviour is to avoid ultraviolet radiation. Alternatively, an additional adaptive value, possibly preadaptation (a shift in the significance of the photoreceptor), could be to optimise host-finding by utilising UV contrast vision. The latter interpretation is conceivable due to the observed aggregation of copepodids at $20 \mathrm{~cm}$ depth when exposed with the combination of UV and VIS; under these conditions the water column above the animals would be illuminated with ultraviolet light and UV contrast vision would be possible.

Photosensitivity of the nauplius eye has been investigated by observing animal responses at different wavelengths. The copepod Epilabidocera longipedata did not show sensitivity to UV-B (Damkaer \& Dey
1982). Hessen (1994) reported an immediate response among 3 different clones of the freshwater cladoceran Daphnia pulex when exposed to light with a spectral transmission maximum at $312 \mathrm{~nm}$, which is in agreement with our findings. Aarseth (1997), using the very same lamp as Hessen, found that the holopelagic copepod Acartia clausi responded immediately by downward migration when exposed to ultraviolet light, both with and without additional visible light, whereas A. clausi were photopositive when exposed to visible light only (a narrow directed beam, fibreoptic lamp). The discrepancy between Damkaer \& Dey (1982) and our findings might be due to the prehistory of the animals. Calanus finmarchicus were collected from deep water, whereas $E$. longipedata were sampled from the surface. This could have influenced the sensitivity of photoreceptors. It is also possible that $C$. finmarchicus responded to UV-A, due to the broad spectral transmission of the lamp we used. The latter interpretation is in agreement with Smith \& Macagno (1990) and Cronin et al. (1994), who revealed spectral sensitivity maxima to UV-A in crustaceans with compound eyes. Moreover, it is possible that sensitivity to UV-A might also give the copepods an increased utilitarian value compared to sensitivity to UV-B, because of the differences in the photon flux

Positive phototaxis in laboratory experiments, as we found among copepodids of salmon lice using diffuse visible light from above, has also been reported by Heuch (1995). Bron et al. (1993) showed that the photopositive response in salmon louse copepodids increased with the light intensity. Such behaviour, however, does not coincide with observations in situ, and the anomalous response in the laboratory has been suggested to be an artefact as a result of the experimental stimulus being a narrow, directed beam (Forward 1988). What if the photopositive behaviour observed in the laboratory reflects the 'normal behaviour' of copepodids when only some of the photoreceptors are stimulated? It might also be important to consider the prehistory of the animals, regarding adaptation of photoreceptors, when interpreting the results.

The discrepancy in behaviour between salmon lice, which responded by a slightly downward migration and the panic reaction by Calanus finmarchicus could be explained by different experimental conditions and/or the biological and ecological differences. A possible interpretation of the experiments with $C$. finmarchicus is that the descent at sunrise would be fast when UV-wavelengths are present. Such a fast descent after sunrise has been reported for $C$. finmarchicus from the Clyde Sea area (Nicholls 1933) and the Gulf of Maine (Clarke 1934). A dawn rise prior to the fast descent to the day depth is known (Russell 1925, Clarke 1934, Cushing 1951). This upward migration 
takes place in a 'window' when the solar radiation is low in UV-wavelengths, due to the low declination of the sun. Clarke (1934) found that when the downward migration eventually was triggered off, the copepods descended fast from the surface waters. According to Clarke (1934, p. 437) 'a higher intensity is required to initiate the migration than is required to cause it to continue'. Such an observation could be explained by the concept of 'present or not' of distinct wavelengths, and may be reflected in the intense swimming triggered by ultraviolet light in our experiments. On the other hand, we would not explain a descent to water depths far below those where ultraviolet light is potentially damaging as an adaptation to avoid the toxic effect of these wavelengths.

Lethal ultraviolet light may have been a strong and persistent selective force at an evolutionary time when distinct wavelengths of light stimulated the cerebrum via the nauplius eye and resulted in avoidance behaviour in some copepods. In addition, we do not see any obvious reason why this pathway of signals and responses could not have evolved in part under the influence of an additional selecting agent, e.g. a visually feeding planktivore. Such adaptation could be the basis for the intense swimming behaviour triggered by ultraviolet light, as in Calanus finmarchicus, or the evolution of highly sensitive photoreceptors (cf. Frank \& Widder 1996). The findings of Gliwicz (1986) might illustrate our point; he reported on the DVM in the copepod Cyclops abyssorum in the Tatra Mountains. In the lake without predatory fish the DVM was only marginal, and Gliwicz suggested that the difference between day and night depth in this lake could be attributed to phototoxicity. In 2 lakes stocked with Salvelinus fontinalis for 5 and 25 yr respectively, the DVM increased but the differences between noon and midnight depth distributions were not significant in either of them. In lakes populated by char for millennia, however, the differences between noon and midnight were significant. Moreover, with the type of eye found in salmon lice, UV contrast vision is possible, perhaps giving rise to a phenotypic response to the presence of planktivore fish, triggered by a visual cue. That a copepod can respond to a visual cue has been shown for Acartia hudsonica (Bollens et al. 1994).

We find it likely that different photoreceptors, as described by Smith \& Macagno (1990), could actually be utilised by the copepods studied, and we assume that such a capability is reflected in the results we obtained with Calanus finmarchicus and Lepeophtheirus salmonis copepodids. Our interpretations of the results reveal that the basic design of such an eye is extremely flexible and, when acted upon by natural selection, can account for much of the diversity observed in crustacean phototactic behaviour. This physiological organ (eye) should be considered when viewing the planktonic habitat as unstructured (cf. Hutchinson 1961), and it could be considered in relation to habitat partitioning in some crustaceans. Weider (1984) pointed out that there is a genetic component in the vertical migration pattern and in habitat partitioning in Daphnia pulex. However, the underlying mechanism explaining the segregation is unknown. Similar findings were also revealed for Daphnia magna (DeMeester 1993), a species which is known to possess 4 distinct photosensitivity maxima. Thus, the phototactic behaviour in some crustaceans could depend upon how the eye is 'utilised' by the actual species, clone or brood.

There is strong evidence that light controls diurnal migration. Different theories explaining how light triggers of the diel vertical migration pattern have been reviewed by Cushing (1951) and Forward (1988), where the 'relative rate of change theory (RLC)' has been given strongest support (Forward 1988, Ringelberg et al. 1991, Ringelberg 1995, vanGool 1997). This theory cannot, however, explain our results, which indicate that behaviour was wavelength specific. Moreover, the RLC-theory reflects neither the physiological capacity of an eye, as described here, nor the diversity in vertical migration. The RLC theory states that the downward swimming continues as long as the light changes exceed the RLC-threshold (vanGool 1997). This is, however, not the case for Calanus finmarchicus. Due to the attenuation of light in water, the descending animals may be subject to a relative decrease rather than a relative increase in light intensity, as Clarke (1934) reported for C. finmarchicus.

It seems a paradox that the copepod response to light changes during the day; descending animals at sunrise are photonegative whereas they must be photopositive at sunset to swim back up. Thus, the ascent may be explained by a secondary causal factor, e.g. hunger. Even though hunger might be an important factor in DVM, the photopositive and -negative response could be triggered by the stimuli of different photoreceptors, as we have shown in the laboratory. At any rate, at present we do not agree with the statement of Forward (1988, p. 375): 'There is no good evidence that wavelength specific behaviour is involved in vertical migration.'

Acknowledgements. We appreciate the comments of an anonymous referee that substantially improved the manuscript.

\section{LITERATURE CITED}

Aarseth KA (1997) Ultrafiolett stråling og det marine miljø. Hovedfag, Department of Biology, University of Oslo 
Anderson A, Nilsson DE (1981) Fine structure and optical properties of an ostracod (Crustacea) nauplius eye. Protoplasma 107:361-374

Bollens SM, Frost BW, Thoreson DS, Watts SJ (1992) Diel vertical migration in zooplankton: field evidence in support of the predator avoidance hypothesis. Hydrobiologia 234: 33-39

Bollens SM, Frost BW, Cordell JR (1994) Chemical, mechani$\mathrm{cal}$ and visual cues in the vertical migration behaviour of the marine planktonic copepod Acartia hudsonica. J Plankton Res 16:555-564

Bron JE, Sommerville C, Rae GH (1993) Aspects of behaviour of copepodid larvae of the salmon louse Lepeophtheirus salmonis (Kroyer, 1837). In: Boxshall GA, Defaye D (eds) Pathogens of wild and farmed fish: sea lice. Ellis Horwood, Chichester, p 125-142

Brooker Klugh A (1929) The effect of the ultra-violet component of sunlight on certain marine organisms. Can J Res 1 : $100-109$

Clarke GL (1934) Further observations on the diurnal migration of copepods in the Gulf of Maine. Biol Bull 67:432-448

Cronin TW, Marshall NJ, Quinn CA, King CA (1994) Ultraviolet photoreception in mantis shrimp. Vision Res 34 $1443-1452$

Cushing DH (1951) The vertical migration of planktonic Crustacea. Biol Rev Camb Philos Soc 26:158-192

Damkaer DM, Dey DB (1982) Short-term responses of some planktonic crustacean exposed to enhanced UV-B radiation. In: Calkins J (ed) The role of solar ultraviolet radiation in marine ecosystems. Plenum Press, London, p 417-427

Dawkins R (1996) Climbing mount improbable. WW Norton, New York

DeMeester L (1993) The vertical distribution of Daphnia magna genotypes selected for different phototactic behaviour: outdoor experiments. Arch Hydrobiol Suppl 39: $137-155$

Dey DB, Damkaer DM, Heron GA (1988) UV-B dose/doserate responses of seasonally abundant copepods of Puget Sound. Oecologia 76:321-329

Elofsson R (1966) The nauplius eye and frontal organs of the non-Malacostraca (Crustacea). Sarsia 25:1-128

Forward RB (1988) Diel vertical migration: zooplankton photobiology and behaviour. Oceanogr Mar Biol Annu Rev 26: $361-393$

Frank TM, Widder EA (1996) UV light in the deep-sea: in situ measurements of downwelling irradiance in relation to the visual threshold sensitivity of UV-sensitive crustaceans. Mar Freshw Behav Physiol 27:189-197

Fraser JH (ed) (1968) Zooplankton sampling. Monogr Oceanogr Methodol 2:1-174

Gliwicz MZ (1986) Predation and the evolution of vertical migration in zooplankton. Nature 320:746-748

Hessen DO (1994) Daphnia responses to UV-light. Arch Hydrobiol Suppl 43:185-195

Heuch PA (1995) Experimental evidence for aggregation of salmon louse copepodids (Lepeophtheirus salmonis) in step salinity gradients. J Mar Biol Assoc UK 75:927-939

Heuch PA, Parsons A, Boxaspen K (1995) Diel vertical migration: a possible host-finding mechanism in salmon louse (Lepeophtheirus salmonis) copepodids? Can J Fish Aquat Sci 52:681-689

Hutchinson GE (1961) The paradox of plankton. Am Nat 882 $137-145$

Jerling HL, Wooldridge TH (1992) Lunar influence on distribution of a calanoid copepod in the water column of a shallow, temperate estuary. Mar Biol 112:309-312
Jerlov NG (1950) Ultra-violet radiation in the sea. Nature 166 $111-112$

Kabata Z (1979) Parasitic Copepoda of British fishes. The Ray Society, London

Lampert $W$ (1989) The adaptive significance of diel vertical migration of zooplankton. Funct Ecol 3:21-27

Nagasawa $K$, Ishida $Y$, Ogura $M$, Tadokoro K, Hiramatsu K (1993) The abundance and distribution of Lepeophtheirus salmonis (Copepoda: Caligidae) on six species of Pacific salmon in offshore waters of the North Pacific Ocean and Bering Sea. In: Boxshall GA, Defaye D (eds) Pathogens of wild and farmed fish: sea lice. Ellis Horwood, Chichester p 166-178

Nicholls AG (1933) On the biology of Calanus finmarchicus III. Vertical distribution and diurnal migration in the Clyde Sea area. J Mar Biol Assoc UK 19:139-159

Ohman MD, Frost BW, Cohen EB (1983) Reverse diel vertical migration: an escape from invertebrate predators. Science 220:1404-1407

Pennington JT, Emlet RB (1986) Ontogentic and diel vertical migration of planktonic echinoid larvae, Dendraster exentricus (Eschscholtz): occurrence, causes, and probable consequences. J Exp Mar Biol Ecol 104:69-95

Ringelberg J (1995) Changes in light intensity and diel vertical migration: a comparison of marine and freshwater environments. J Mar Biol Assoc UK 75:15-25

Ringelberg J, Flik BJG, Lindenaar D, Royackers K (1991) Diel vertical migration of Daphnia hyalina (sensu lationi) in Lake Maarsseveen. Part 1. Aspects of seasonal and daily timing. Arch Hydrobiol 121:129-145

Russell FS (1925) The vertical distribution of marine macroplankton. An observation on diurnal changes. J Mar Biol Assoc UK 13:769-809

Schram TA (1993a) Livssyklus hos lakselus, Lepeophtheirus salmonis; stadienes utseende og biologi. Nor Vetmed 105 $1207-1215$

Schram TA (1993b) Supplementary descriptions of the developmental stages of Lepeophtheirus salmonis (Krøyer 1837) (Copepoda: Caligidae). In: Boxshall GA, Defaye D (eds) Pathogens of wild and farmed fish: sea lice. Ellis Horwood, Chichester, p 30-4?

Smith KC, Macagno ER (1990) UV photoreceptors in compound eye of Daphnia magna (Crustacea, Branchiopoda) A forth spectral class in single ommatidia. J Comp Physiol A $166: 597-606$

Stearns DE, Forward RB (1984) Photosensitivity of the calanoid copepod Acartia tonsa. Mar Biol 82:85-89

Stich HB, Lampert W (1981) Predator evasion as an explanation of diurnal vertical migration by zooplankton. Nature 293:396-398

vanGool E (1997) Light-induced swimming of Daphnia: can laboratory experiments predict diel vertical migration? Hydrobiologia 360:161-167

Weider LJ (1984) Spatial heterogeneity of Daphnia genotypes: vertical migration and habitat partitioning. Limnol Oceanogr 29:225-235

Williamson $C E$, Zagarese $H E$, Schulze PC, Hargreaves $P$, Seva J (1994) The impact of short-term exposure to UV-B radiation on zooplankton communities in north temperate lakes. J Plankton Res 16:205-218

Yoshida M, Milliott N (1959) Light sensitive nerves in an echinoid. Experientia 15:13-14 (cited as in Pennington \& Emlet 1986)

Zaret TM, Suffern JS (1976) Vertical migration in zooplankton as a predator avoidance mechanism. Limnol Oceanogr 21 : $804-813$

Submitted: June 30, 1998; Accepted: February 15, 1999

Proots received from author(s): August 20, 1999 